\title{
Correction to: A novel tumor suppressor protein encoded by circular AKT3 RNA inhibits glioblastoma tumorigenicity by competing with active phosphoinositide- dependent Kinase-1
}

\author{
Xin Xia ${ }^{1,2+}$, Xixi Li ${ }^{1,2+}$, Fanying $\mathrm{Li}^{1,2+}$, Xujia Wu ${ }^{1,2}$, Maolei Zhang ${ }^{1,2}$, Huangkai Zhou ${ }^{1,2}$, Nunu Huang ${ }^{1,2}$, \\ Xuesong Yang ${ }^{1,2}$, Feizhe Xiao ${ }^{3}$, Dawei Liu ${ }^{4}$, Lixuan Yang ${ }^{1,2}$ and Nu Zhang ${ }^{1,2^{*}}$
}

Correction to: Mol Cancer (2019) 18:131

https://doi.org/10.1186/s12943-019-1056-5

In the published article [1], an error was noticed in Fig. $6 \mathrm{~b}$. The western blot results were reversed between the overexpression group and the knockdown group of circ-AKT3. The corrected and updated Fig. 6 is provided below. This error does not affect the findings or conclusions of the article.

\section{Author details}

'Department of Neurosurgery, The First Affiliated Hospital of Sun Yat-sen University, No 58, Zhongshan 2 Road, Guangzhou, Guangdong Province 510080, People's Republic of China. ${ }^{2}$ Guangdong Provincial Key Laboratory of Brain Function and Disease, Precise Medicine Institute, The First Affiliated Hospital of Sun Yat-sen University, Guangzhou, Guangdong 510080, People's Republic of China. ${ }^{3}$ Department of Scientific Research Section, The First Affiliated Hospital of Sun Yat-sen University, Guangzhou, Guangdong Province 510080, People's Republic of China. ${ }^{4}$ Department of Pathology, The First Affiliated Hospital of Sun Yat-sen University, Guangzhou, Guangdong Province 510080, People's Republic of China.

\footnotetext{
* Correspondence: zhangnu2@mail.sysu.edu.cn

${ }^{+}$Xin Xia, Xixi Li and Fanying Li contributed equally to this work.

'Department of Neurosurgery, The First Affiliated Hospital of Sun Yat-sen University, No 58, Zhongshan 2 Road, Guangzhou, Guangdong Province 510080, People's Republic of China

${ }^{2}$ Guangdong Provincial Key Laboratory of Brain Function and Disease, Precise Medicine Institute, The First Affiliated Hospital of Sun Yat-sen University, Guangzhou, Guangdong 510080, People's Republic of China

Full list of author information is available at the end of the article
}

(c) The Author(s). 2019 Open Access This article is distributed under the terms of the Creative Commons Attribution 4.0 International License (http://creativecommons.org/licenses/by/4.0/), which permits unrestricted use, distribution, and reproduction in any medium, provided you give appropriate credit to the original author(s) and the source, provide a link to the Creative Commons license, and indicate if changes were made. The Creative Commons Public Domain Dedication waiver (http://creativecommons.org/publicdomain/zero/1.0/) applies to the data made available in this article, unless otherwise stated. 


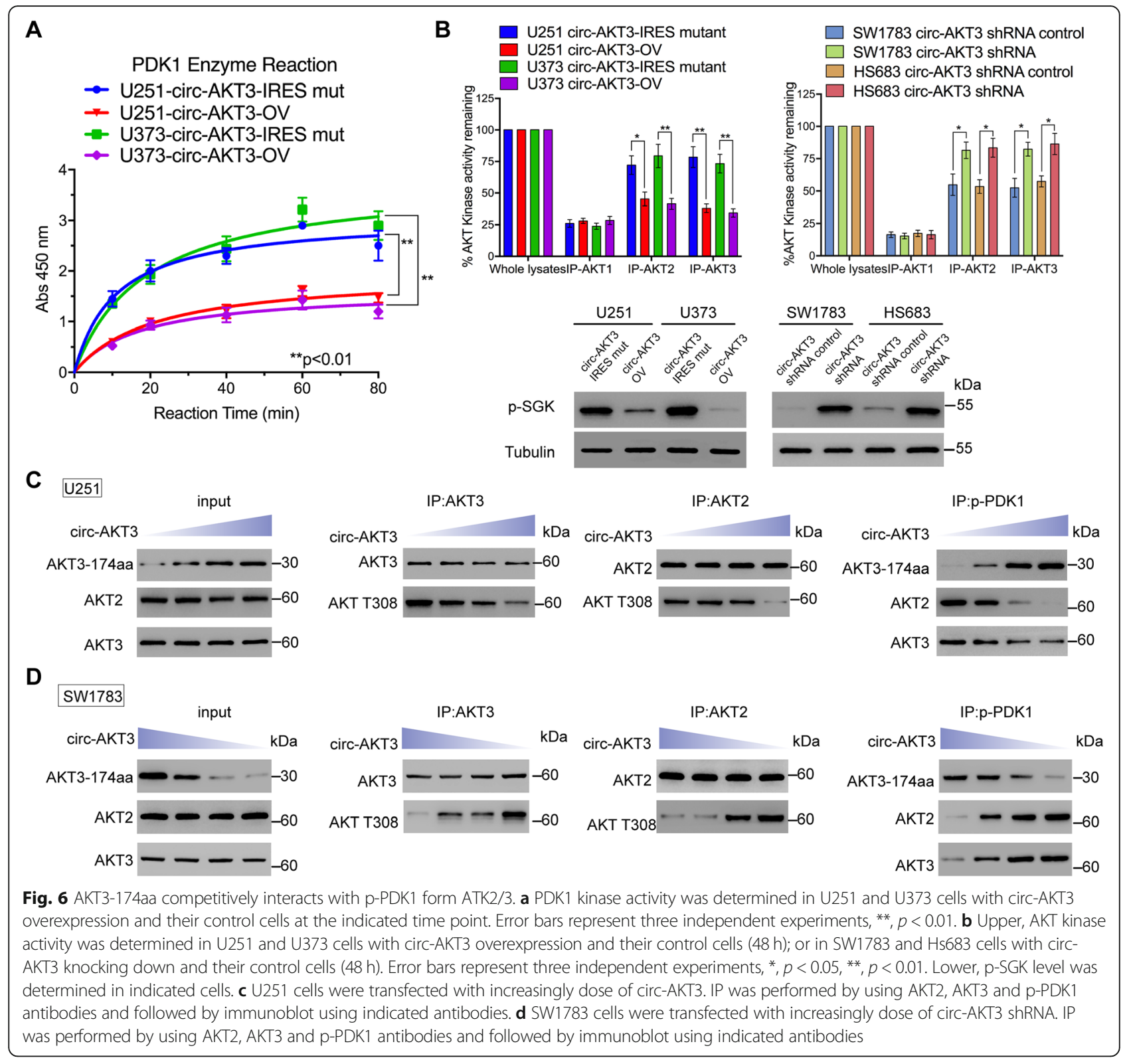

Published online: 29 October 2019

\section{Reference}

1. Xia X, Li X, Li F, Wu X, Zhang M, Zhou H, Huang N, Yang X, Xiao F, Liu D, Yang L, Zhang N. A novel tumor suppressor protein encoded by circular AKT3 RNA inhibits glioblastoma tumorigenicity by competing with active phosphoinositide-dependent Kinase-1. Mol Cancer. 2019;18:131. https://doi. org/10.1186/s1 2943-019-1056-5. 